\title{
Laughing out Loud: The Popular Politics of Schadenfreude in Joker
}

\author{
Nishat Atiya Shoilee \\ Lecturer, Department of English and Humanities, University of Liberal Arts Bangladesh. \\ ORCID: oooo-ooo2-7170-5513. Email: nishat.atiya@ulab.edu.bd
}

\begin{abstract}
This research attempts to identify and analyze the relatively less explored aspects of schadenfreude as a primary currency in an American attention economy as depicted in the 2019 movie, Joker. It discusses how the protagonist's comedic ambition to become a live performer falls short of its aim, as he feels inclined to embrace the negativity bias in his city and its questionable amusement impulses. Maintaining the appealing and appalling forces of liking and disliking; the deservingness of others' good and bad fortunes; desirability for self-evaluation; rivalry and intergroup factors- the paper pursues schadenfreude as the masses' new opiate. It analyzes the American renaissance of self-effacement and public humiliation in light of its mass media environment that had been abandoning meaningful stories for ticklish delights since the mid-nineties. Both primary and secondary data are used to reinforce an end result which takes the current glocal reality to be the distinct creation of a bizarre comedic moment that both defies and weaponizes a mediafication of its consumers' emotional health.
\end{abstract}

Keywords: Schadenfreude, comedy, laughter, American humor, sociopolitical identity, transgression

\section{Introduction}

Melanesians still enjoy telling the story of how an Australian government minister visited the village, got annoyed because the villagers wouldn't do what he wanted, drove away in a huff and crashed into a tree ... The glee here [is] felt at incompetence - not just of skiers face-planting in the snow, but at screw-ups of 'implausible' magnitude. (Smith, 2018, para. 2\&6)

The concept of laughter etymologically goes back to the German verb, lachen and Old English, hliehhan- an onomatopoeic label mimicking the very sound of a laugh itself. Over time its original pronunciation was lost, becoming the Middle English laughen and eventually 'laugh.' It is not just the word that has been subject to culturohistorical changes but also the ways it connotes and is conceived have undergone critical speculations over the recent years. For instance, one cannot deny that the politically problematized versions of contemporary laughter have a certain "news quality" to them (Smith \& Dijk, 2018, p. 294), be it an everyday experience of watching the news on TV or 'LOLing' around with friends. Otherwise considered an emotional response in a given situation, one such variant of laughter can be analyzed through the intricate lens of schadenfreude - a compounded sentiment of schaden and freude, respectively meaning 'harm' and 'joy' in German triggered by "an event presumed to be undesirable for someone else" (Ortony et. al, 1988, p. 13).

The word first appeared in English writing by Richard Chenevix Trench in his 1853 bestselling book on philology, On the Study of Words. While 'gloating' might be seen as an English single-word equivalent of the original German expression, it is more about inappropriately (c) AesthetixMS 2021. This Open Access article is published under a Creative Commons Attribution Non-Commercial 4.0 International License (http://creativecommons.org/licenses/by-nc/4.o/), which permits non-commercial re-use, distribution, and reproduction in any medium, provided the original work is properly cited. For citation use the DOI. For commercial re-use, please contact editor@rupkatha.com. 
celebrating one's achievement than focusing on others' failures that can be detected in schadenfreude. Commonly treated in religions as a shameful act and more frivolously portrayed in paintings like Return to the Convent (1868) by Eduardo Zamacois y Zabala and even in literature two centuries before (Don Quixote by Miguel de Cervantes), it has been an all-too-human principle since time immemorial, though the "mysterious and terrible passion remained without a name" for a long time (Smith, 2018, para. 8). Similar to French joie maligne; Danish skadefryd; Mandarin xing-zāi-lè-huò; Russian zloradstvo; Melanesian banbanam; Roman malevolentia, or Greek epichairekakia, schadenfreude in different cultures and literatures only implies humans have a long history with the humiliations and failures of others. The suspicious aspects about it might not be discovered anew but arguably the academic urgency to study and scrutinize this mass phenomenon has never been so great as today.

As anticipated, any civil society, by all means, finds the thought of someone deriving pleasure at another person's misfortune highly objectionable since it challenges the very anatomy of the urbane Enlightenment and its gentility standards. However, as H. Bergson defines man as "an animal which often laughs" - he might equally be acknowledged as "the one who is laughed at" - making laughter a two-way process (1956, as cited in Williamson, 2008, p. 45). And the exponentially growing media mania of laughing at people falling, slipping, tripping, hitting the ground or just making a 'fool' out of themselves suggests the same as evidenced in algorithmic platforms like Facebook, Snapchat, Whatsapp, Reddit, Tumblr, Tiktok, YouTube, Twitter, Pinterest, or any other typical American late-night TV shows. The implicit cultural policies of influencing and thereby, reorienting an otherwise ethical question about the deservingness of others' good and bad fortunes refer to an entitlement that falls under the discourse of schadenfreude; and this paper will attempt to identify the politics of that collective behavior in Joker, a 2019 American psychological thriller film directed, produced and co-written by Todd Phillips.

Loosely adapted from Batman: The Killing Joke (1988) and The Dark Knight Returns (1986) but largely inspired by 1970's character studies and Martin Scorsese films (particularly Taxi Driver and The King of Comedy), the plot of Todd Phillips' Joker has a protagonist named Arthur Fleck (starring Joaquin Phoenix) who is a party clown and aspiring stand-up comedian. In a 1981 Gotham city, he embodies an alternative standalone origin story for Joker, one of the most iconic villains from the original DC Batman comic series (1939). Containing the media's favorite fictional persona non grata of 2019; scandalous portrayals of neo-liberalism, woke culture, and incendiary brinkmanship; romantic illustrations of villainy, violence, incel communities, mass shootings, and psychiatric disorders, or formulaic clichés of a "gimmicky, disingenuous boring good-guy-gonebad" (Wilkinson et al., 2019, para. 12), Joker can be stated to easily fit the shoes of critical condemnation and public appraisal. In this case, the discursive relationship between critics' choice and popular taste remains at odds as the movie was an instant major box office success (sixthhighest-grossing film of 2019) while condemned by multiple esteemed review sites, newspapers and national TV channels as a failed project at realizing "society's alienation of a disenfranchised white man" that other Hollywood productions like Network (1976), A Beautiful Mind (2001), or American Psycho (2002) had already successfully accomplished (Wilkinson et al., 2019, para. 15). However, what is interesting and has been less talked about is how the types of laughter used in this motion picture portray the process of essentializing a conditioned comedy which purposefully communicates a public feeling of schadenfreude, and in turn complicates the popular espousal of humor and laughter as a vassal of commercial interest. 


\section{The Liking and Disliking Principle in Joker}

Speaking of some of the major categories of laughter relating to schadenfreude one can identify in Joker, there are several: 1) the frequent, uncontrollable, pathological convulsions of a psychotic patient; 2) a politically intrigued smirk meant to mock gangster capitalism and pretentious philanthropists (as depicted by the Wayne family); 3) the canned laughter played in the background of late-night TV shows; 4) the chortles of an audience at a live program of stand-up comedians; 5) the forced chuckles which serve as a defense mechanism and deny the plights of life (Arthur losing his job, or knowing the truth about his mother); 6) the muffled cackle of masked vigilantes ready to confront a city of crimes, 'litters,' 'super rats' and 'garbage strikes' (Phillips, 2019); 7) the rare guffaws prompted by genuine moments of shared interest (between Arthur and Sophie), and 8) the last enigmatic snicker of Arthur himself at the closing scene that his audience simply "wouldn't get" (Phillips, 2019). No longer an elementary expression of joy or happiness, the combined discourse of many a laughter in Joker rather deconstructs those determinants that have propagated the apocryphal celebration of USA's post-broadcast comedy/reality shows.

Now whether or not Todd Phillips failed to commit to a singular vision of serious dramaturgy (previously recorded to make "crude and crass" comedies, as reported by Vic Holtreman from Screen Rant in his 2013 review of The Hangover trilogy) and created a mere cultfavorite or a DC grimdark agitprop simply re-skinned in the shadow of two classic pieces of Scorsese, that is a different matter of concern. What holds our interest here is the entrepreneurial subjectivity of Gotham's mass media in an entertainment landscape where a mentally ill loner struggles for visibility and throughout his journey discovers a nation's great capacity for cultural distraction. Dramatizing a dystopian world fed by both individual as well as societal instabilities and counterproductive idée fixes of a synthetic schadenfreude, the film shows how one man's humiliation can be legitimized to become another man's pleasure. Therefore, the paper will attempt to capture Joker's depiction of mass access to comedy shows as a studio-based genre affected by an artificial 'televisuality' (Williamson, 2008, p. 11), naturalizing public humiliation and producing schadenfreude as an inevitable end product.

According to the liking and disliking principle of schadenfreude as proposed by Smith and Dijk in their 2018 essay "Schadenfreude and Gluckschmerz," it is our "prior attitudes or sentiments we have toward the person who has suffered or prospered" (p. 294) which determine our immediate emotional reaction of either positive or negative relevance. One of the opening sequences of Joker, for instance, includes Arthur wearing his bright clown clothes and dancing around with a sign to draw attention to a big sale going on in a music store which will soon go out of business. Shortly a group of teenagers about to cross the road begin to laugh at him, knock the sign out of his hand, kick him in the back, run away with the sign so that he follows, and keep hitting the solitary saunterer with his sign till he is left out of breath in a dark alley. The following scene involves yet another antagonistic response to Arthur as he tries to make a little girl in a bus giggle and her mother already annoyed, complains, "Can you please stop bothering my kid?" (Phillips, 2019). From the way each of Arthur's actions seems to trigger a sense of almost involuntary yet negative subjective consequence, it seems that a series of events has been set forth inside a system that somehow emancipates its people to culture a guilt-free schadenfreude where it is just as liberating and 'fun' to verbally or physically abuse someone 'disagreeable' as it is to watch a ten-minute long fail compilation.

The presupposition of hostile action tendency continues when Arthur loses his job and on his way home meets three vindictive Wall Street young men who demonstrate an unhealthy interest in the motley man sharing their subway compartment. The reflexive synchrony of a rough (the rest 
of the cast) and a passive (Arthur) behavioral pattern simultaneously substantiates what follows as another significant criterion to understand schadenfreude as a mass rhetoric and that is whether or not the subject of concern deserves what has happened to them. For instance, the audience does not hesitate to reproach the loud, obnoxious, and clearly drunk men as they tease a lady and then beat Arthur sadistically almost to death for no apparent reason. Therefore, when Arthur ultimately brings out the gun of his friend he was safeguarding and shoots them one after another, the very people watching the movie perceives this act to be almost gratifying in a paradoxical interplay of Janus-faced pleasures "felt, but not spoken about" (Puschak, 2017, 3:02), thereby justifying one of the top taglines of the film, "You get what you $\mathrm{f}^{* *}$ deserve!" (Phillips, 2019)

As a result, those responsible for their own misfortune are seen as deserving a comeuppance and a "justified" schadenfreude is felt on the observers' part that relates to "a balanced set of outcome relations" (Smith and Dijk, 2018, p. 295). With the socio-economically superiors cut down to size, "a pleasing, warranted social comparison boost" (Smith and Dijk, 2018, p. 296) encourages gangs of domesticated 'underdogs' to feel like wild wolves for a night, wear joker masks and join in processions to reduce the city into ashes. Thus, the "had it coming" factor resulting from public exposure of hypocrisy perforce intensifies an already observed schadenfreude out in the open. A similar assumption applies to another scene where Arthur, in his bildungsromanic process of becoming the joker as originally known in Kane and Finger's Batman universe, shoots Murray in the head and on the other end of the street the Wayne family is murdered with solely Bruce Wayne (later, Batman) survived. Here, schadenfreude can be seen as a form of herd respite wherein "we perceive our disadvantage as unalterable and the envied person's advantage as undeserved" (Smith and Dijk, 2018, p. 297). On that account, the palpable divide between the haves and the have-nots, the smart and the scruffy, the good and the bad - is experienced with an "opportunistic pleasure, a spectator sport" (Smith, 2018, para. 19) - a judiciary kind of schadenfreude relished all too well.

\section{"No one's laughing now!" : American Humor in the 1990 s}

Having said all that, the idea of an individual being the rightful recipient of an outcome directly followed by what they have said or done becomes a choice of risk when it is about performing standup comedy, as we can see in Arthur's tireless pursuit of a space of his own in a professional comedy show. As Borns states, stand-up comedy is not just "live, but living - an organic, growing, developing monologue that is as reactive as it is active" (1987, as cited in Wilson, 20o8, p. 74) in front of an audience trained and self-made at the same time. To understand the imaginary premise of TV comedy in 1981's Gotham as illustrated in the film (heavily influenced by the look and atmosphere of the 8o's New York), it is important that we remember how stand-up comedy as it is publicized today saw its rise in the USA.

America, in the period from the late 1970s until the mid-1990s saw a significant reterritorialization of comedy shows not simply at hotels, restaurants, resorts or clubs, but at digital venues such as 45 " records, LPs, radio and television, including the birth of Comedy Central, a cable channel entirely dedicated to stand-up comedy. First, there were stand-up concert films (by Richard Pryor; Eddie Murphy; Chris Rock; George Carlin; Dave Chappelle; Robin Williams to name a few), improvisational comedy shows (Whose Line Is It Anyway?), and video clip television series (America's Funniest Home Videos). Then, there was an explosion of present-day sitcoms, animation shows (like The Simpsons; South Park; Family Guy; American Dad; more recently, BoJack Horseman), late-night variety shows (Saturday Night Live), sketch comedies, and talk shows usually hosted by popular stand-up comedians (David Letterman; Jimmy Fallon; Jimmy Kimmel; Ellen DeGeneres; Conan; Seth Meyers; Stephen Colbert to mention some). Primarily viewed as a powerful 
transgressing weapon against meta-narratives and homogenizing intents to promote a culture that is politically 'woke,' stand-up comedy maintained its popularity throughout the first decade, featuring issues like subjective freedom and cultural plurality. Over the next two decades, however, this aesthetic of the carnivalesque began to develop symptoms that more revolved around instant gratification; cancel culture; newspeaks; obscenity; infomercials; whataboutism; inflammatory jokes; slurs; name-calling; physical attacks; mockery; harassments, and prioritization of entertainment value over serious national/international bones of contention. Soon, alternative TV journalism became a hybrid package of amnesiac amusement and fake political commentary.Therefore, the type of laughter these commercially successful comedy shows induced as a definitive outcome of their 'humorous' content no longer remained innocent and unsuspecting after a while:

Laughter may or may not be a judgment, but as it is often expressed in the aggregate form of group laughter, and as it is an ephemeral expression of the moment, we may not be able to discern its [true] meaning at times. (Wilson, 2018, p. 12)

Because of this, a population systematically trained to live on the extreme edges of an orchestrated reality that might reciprocate either in any sudden productive or destructive direction, can hardly differentiate the factual from the unreal, the reality from a parody, the serious from the unserious, and the meaningful from the meaningless. As we can see in Joker, Arthur is free of such complications and hence, has to keep conscious notes of which parts of a joke the audience might or might not find particularly 'laughable,' in other words, the jokes that will sell and those that will not. It is his critical unawareness of the 'real comedy' which makes him smile at rather grim things and renders his public impression as that of a pervert around the corner "who thinks if you just keep laughing, it'll somehow make you funny" (Phillips, 2019). Consequently, Murray Franklin's show decides to invite the unfunny joker of the town whose sheer stupidity and childlike confidence in himself will be met with elation from a specific niche segment of the audience, turning out to be too strong a schadenfreude material for media executives to resist.

And herein lies the success of Joker where an anti-hero eventually garners collective support both among the disruptors in the film and the blue-collar section of the audience who share an identical resentment against exploitative infrastructures, be it one of the entertainment world or political administration. In a dialectical alignment of meta-theatricality, the viewers of the movie identify with the viewers in the movie attending Murray Franklin's show. They understand how the entire live program (shooting style; lighting; editing techniques; narrative structure; voiceover; laughter track; colorful curtains; and music) is pervasively engineered upon principles of humiliation and othering, an unjustifiable schadenfreude meant to hurt, to judge, to critique, to abandon and "treat one like trash" (Phillips, 2019). Considering that a host's personality ultimately shapes the tone of his/her show, defining the trademark for which the show should be known Murray's live program seems to target the failed humor of people with a limited intellectual sophistication - involving even Murray's own son, "the new one, the-not-so-bright-one" (Phillips, 2019). Later, the grotesque grimace Arthur paints with his own blood professing to catalyze the lampooned clowns into starting a rampage makes it even more obvious, as in how the riotous mindset was already always there - despite the media mania of utopian success and cosmetic values - dormant yet ready to erupt among the same people inculcated to laugh and be laughed at by themselves.

Mimicking the post-network USA's consumerist agenda to popularize tokenist production in a multichannel marketplace, Joker's world from the late nineties demonstrates the downfall of a community predicated on euphemistic hysteria and false American Dream. In a parallel connection, 
the old, dark and deformed Gotham tends to reflect any given domestic backdrop in the now where silent moments of exchanging uncomfortable glances even within a familial setting are offered relief mostly when a digital gadget is open, playing random content in a loop that decides for us how to laugh and what to laugh at. The intoxicating charade of entertainment, politics, journalism and schadenfreude inevitably gives rise to in-group favoritisms and a lopsided amount of media coverage of the ongoing controversies; it also rationalizes the extreme 'roasting' mechanisms applied in each new 'revelation,' each trendy 'hashtag,' or each 'bombshell report' at speeds that neither permit nor require evaluation:

Thus comedy [...] is not just a field of narrative expectation punctuated by the surprise of laughter or vertiginous enjoyment. It is also epistemologically troubling, drawing insecure boundaries as though it were possible to secure confidence about object ontology or the value of an "us" versus all its others ... It is sensitive because the funny is always tripping over the not funny, sometimes appearing identical to it. (Berlant and Ngai, 2017, p. 3)

\section{Joker and Comedy's Grey Areas}

While it is true that comedy serves as an intuitive bridge between admitting our inefficacies as a species and then confronting them with a satiric intent to fix and restore (as did the Scriblerus and Kit-Cat Club in the early 18th century London), one cannot wholly avoid the surfacing of a probable consequentialist standpoint. The mere chances of an audience wondering "Was that really supposed to be funny?" might be a scenario every possible form of live performance would like to avoid at all costs. For instance, When Murray (starring Robert De Niro who also played the mainstays in The King of Comedy, and Taxi Driver to which Joker is a directorial homage) in his first appearance suggests that the Mayor of Gotham can exterminate super rats from the city by releasing super cats, it produces an instant identification magnet for the people present in his show who can verify this situational humor on a personal level. However, to procure that specific group reaction, "to transmit the vaudeville experience directly into the nation's living rooms" (Williamson, 2008, p. 47), the studio must make sure that everything happens according to the 'lines'; that the already established comedic climate triggers an impetuous peer pressure so that people do in fact, have to find it 'funny.' It is those "certain signs [built] into a work which let us know what the stage wants to be a comedy and wishes us to take it as such" (Mast, 1979, as cited in Williamson, 2008, p. 48). The agenda becomes clear when we see a production assistant waving cue cards in front of Murray that say, "Thank you! Glad you're here. We've got a great looking audience here tonight" (Phillips, 2019), or when digital teleprompters curiously glow every time the audience is supposed to 'applaud' at a particular joke. Also, when Murray insists on Arthur's statements in his interview as "not the kind of humor we do on this show" (Phillips, 2019), it recapitulates the triumph of mainstream comedy and playful escapes at the discredit of a "Frankenstein on a crowded beach" who "doesn't have a punch-line" (Phillips, 2019).

Of course, by reducing the serious to something trivial, comedy still serves its purpose which is making its audience aware of their flaws in a humorous irreality, assuring us "that everybody's in the same boat, and weaknesses are inevitable and universal" (Durgnat, 1969, as cited in Williamson, 2008, p. 51). Nevertheless, when the safe limit is crossed and sensitive issues are neutralized to negotiate and monitor a public taste that suits information shortcut, 'easy fun,' "an assertion of superiority, social cancellation, and imposed embarrassment"' (Gray, 2006, as cited in Williamson, 2008, p. 55), comically challenged individuals like Arthur find it difficult to accept and adapt. With no proper training in comic delivery, timing, prudential wordplays, content, gestures, intonation, stage prompts, or the fundamental elements of decorum and surprise, Arthur 
misunderstands the basic grounds of parodic deviation and its power to represent culture-specific ideologies, here namely those of the USA's. Politicized, depoliticized and then apoliticized over a period of fifty years starting from the mid-nineties till now, the humor business in America has witnessed the rise and fall of burlesques, Chautauqua, and political satires, ultimately steering towards an era of 'straightjacket' jokes (Stebbins, 1990, as cited in Wilson, 2008, p. 10), one-liners and anecdotal wisecracks. Despite a strong claim of reformist agenda, without any doubt these genres have a special inclination for disparagement, discomfort and suppression. In this case, saying 'it's just a joke' does not suffice the long-term sociopolitical aftereffects, signaling a problematic space for an individual (or a community) to express a prejudiced faith and act accordingly with no inhibition. It might seem somewhat reductive to propose that all instances of humor operate this way; but the Joker universe as captured in its mise en scène exclusively attacks a similar homogenization of a counter-cultural identity concerning our immediate comedification of everyday life, namely schadenfreude:

Sometimes it is easy to share our delight, scoffing at the humiliation of the TV talent show contestant, reposting memes of a disgraced politician's resignation speech, or sharing barely suppressed glee with our fellow classmates when the teacher farts ... spasms of relief which accompany the bad news of our annoyingly successful friends and relatives. (Smith, 2018, para. 4)

Seen from a purely profit-oriented perspective, the institutional production and distribution of television/online shows eventually rely on raising the demographic growth of viewership and transmitting advertisements. For the USA, the à la mode viewers' checklist usually tends to include "hip, sophisticated, urban-minded, mostly white, liberal, college-educated, upscale 18-to 49-yearolds with liberal attitudes, disposable incomes, and a distinctively edgy, ironic American sensibility" as revealed in the Nielsen ratings of national channels like NBC, ABC, CBS, Fox and CW (Williamson, 2008, p. 68). The same target audience is applicable for other independent sites on the internet, too. To address this desperate competition among the existing TV networks and social media platforms, entertainment entrepreneurs tend to devise what Corner has labeled as "the trap of populist descriptivism" (1994, as cited in Williamson, 2008, p. 64) mostly identified in a comedy show where a prescribed documentation of so-called popular experiences takes on an affirmative reception by its viewers. In this case, it does not matter whether the content covered is authentic or not as long as the presentation style is entertaining and persuasive enough, thereby increasing the conditional likelihood of people mistaking a false notion about themselves to be true.

For example, when Arthur is seen taking notes from a professional performer during a live stand-up performance, one point that he writes stands out because of the way it is highlighted in bold fonts meant to attract our attention, "Sexy jokes always funny" (Phillips, 2019). There is no denying that the suggestive property of those jokes has an impact on the audience as they process the sequentially organized and precisely placed information to mirror it later in a visceral reaction (laughter). Nevertheless, once Arthur registers the thought in his lived reality while contemplating a suspension of disbelief, the scene reiterates that the audience too, in fact, is bargaining the soundness of their behavior as simulated which apparently, loves sex jokes. The subtle yet effective persuasion of a comical aftermath thus might soften and systematize an attitude which perhaps is not true for all who are watching or listening. However, because of the very nature of the representation, what used to be false and funny from a safe distance might run the risk of becoming true and serious when deemed common and admissible. With that being the case, laughter here becomes a political rhetoric that targets at creating a worldwide monoculture of similar networks, producers, consumers, and managements structures. 


\section{Joker's Comic Relations: A Behavioral Analogy}

Arguably, exposure to hostile humor can provide an "emotional catharsis or release of repressed aggression" (Ferguson and Ford, 2008, p. 286), decreasing the chances of troubling impulses. Yet, our morbid contemporary fascination with the recovery of a repressed self-esteem insists on downgrading "the unfortunate, stupid, clumsy, morally or culturally defective" (Gruner, 1997, as cited in Ferguson \& Ford, 2008, p. 289). The corporate intelligentsia especially finds these sorts of contentious contents favorable since they pertain to its ideals of competitive advantages and market opportunities. The Darwinian game of surviving this cutthroat automaticity requires one to absorb the need for a safe relief and in that, humor makes a grand entrance. It provides the audience with an illusion of sudden glory, a momentary victory over somebody else as the tone of the jokes oscillates between one that is mildly disparaging and another, brutally intolerant. This frame of comic reference explains the immense popularity of comedy/reality shows nowadays in the age of information which advertizes "remarks that (are intended to) elicit amusement through the denigration, derogation, or belittlement of a given target (e.g., individuals, social groups, political ideologies, material possessions)" (Ferguson and Ford, 2008, p. 280). From fraters' clubs to blacktie dinners, the otherwise innocuous comedy shows now seem to enable the same contradictions they claim to diminish and reinterpret in a productive way, for "how does comedy stage its own ... alleviating, social-distance-gauging missions differently, if people are increasingly supposed to be funny all the time?" (Berlant and Ngai, 2017, p. 236)

The danger of a superfluous urge to "be happy all the time" here "is not that it increases intolerance within people, but that it creates a social environment more accepting of prejudiced forms of expression" (Ufberg, 2015, para. 16). To dare a disinterested world into admitting that "all I have are negative thoughts" (Phillips, 2019) would be a violation of the norm- a taboo- too fearsome a possibility to even foresee. With a much-sensationalized demand for toxic positivity in social media, it is understandable that promoting commercial merchandise or creating a strong, positive perception of a company/celebrity/influencer/TV network/YouTube channel/personal account on digital platforms is a must for anyone who is trying to make a name in the entertainment industry. In Joker, as Arthur during his interview with Murray tries to make a knock-knock joke about the police informing a lady that her son has died in an accident, people boo at him for not possessing the comedic knowledge required to make them laugh. The hecklers' inference here is not unlikely, bearing in mind that indeed Arthur mistook a tragic event for a true joke; but what is surprising is the undivided readiness of the audience to be a complaint comic alibi and acknowledge in unison at the exact same minute how 'bad,' humorless and a performance of foot-dragging shame the joke really is. Equally, for Arthur, it is an aggrieved sense of having been denied laughter or having had his efforts disrespected and devalued.

Apparently, it seems that "people tend to get more upset when their capacities for enjoyment are questioned or pressured than when their capacities for empathy are tested" (Berlant and Ngai, 2017, p. 242). Therefore, to not laugh in a group can be "experienced as shaming; as condescending; as diminishing"(Berlant and Ngai, 2017, p. 242) and to laugh is an act of obligation than of mere choice. Another popular tagline from the movie "Put on a happy face!" (Phillips, 2019) hence, gets an added conceptual value to it, encapsulating the interconnection between a grin and a chagrin, schadenfreude (the pleasure of one) and gluckschmerz (the pain of the other which produces that pleasure). A critique of the post-millennium America's obsession with happiness, positive-thinking movement and fundamentally avoidant cultural dialogues, Joker delineates a generation which is ideologically lobotomized and lacks emotional resilience. The fact that being in remission or forcing a positive atmosphere does not help someone like Arthur who is rather in 
need of a more compassionate and considerate (also medical) attention proves that overvaluing the collective hype of schadenfreude makes the already paranoid somnambulists feel more culpable, implying their 'lack' of positivity as the sole reason of their unhappiness. The persistent demand for play and fun as 'good and necessary' for social membership thus everywhere inflects what was once known as alienation:

To say that it is comedy that people increasingly come to expect in the kinds of social interaction that take place in all zones of modern life-politics, education, journalism, even religion-is something different from talking about a mode and mood of hyperenjoyment made by the culture industry, which runs on [therefore, manipulates] a great deal of high seriousness as well. (Berlant and Ngai, 2017, p. 237)

Here, the light-hearted disjecta membra traditionally associated with comic leitmotifs and archetypes, seems to gesture at more complicated behavioral issues that are involved in the game of laughing and being laughed at. Susan Purdie's methodological analysis of a comedian's identity construction in her 1993 book, Comedy: The Mastery of Discourse might offer us a new perspective regarding how and why Arthur becomes a living joke himself instead of being the joker, the butt of a joke than a joker of butts. Following the Lacanian manipulation of symbolic register, Purdie stresses that the success of a joke depends on a deliberate transgression of the one-to-one relationship of a signifier to a signified; and that a performer readily invokes more than one "definitionally different signifier or signified in one given semantic space" (1993, as cited in Pye, 2006, p. 56). The playful discourse of multiple signifying structures implies that a comedian is well aware of the logical inconsistencies and semantic deviations he/she has effectively asserted to generate a desirable comic effect. Furthermore, to have the effect confirmed, "the recipients must also acknowledge the joker's aberrant behavior as [a calculated] error" (Pye, 2006, p. 57). The even distribution of semiotic power thus yields a sight where an audience plays rock paper scissors with the comedian, as they both take turns to make each other feel empowered in the meaning-making process. But before that space of intellectual equilibrium is created and the humorist is offered the accolade of "a master of discourse," he/she needs to establish themselves as a "discursively strong persona, a full subjective agent" (Pye, 2006, p. 65). This earnest commitment of a performer helps him/her eliminate the nervous energy that might be emanating from the beholders of the playhouse, plagued by the latent fear of defying traditions and trespassing borders.

A failure at constructing a powerful identity as such would instantly work as a boomerang and turn the comedian himself into a butt in humor, a schadenfreude figure to ridicule. Although comic contexts are characterized by a lack of serious consequences and viewers are guaranteed often during an on-screen plight that "the characters will not suffer any adverse effects as a result of their reaction (laughing)" (Williamson, 2008, p. 46), sometimes a reverse picture just might be unavoidable. Hence, a mental misfit Arthur who does not even have full control over his body because of a neurological condition, cannot help rearing a performance anxiety which obliterates any gap between himself, the joke-teller; the audience; and the subject of humor, the 'missing butt.' For an aspirant performer who has no prior talent or skill in the act of performing, the awkward void of ennui that ensues after his failed attempt must be filled with a counterfeit response, making the humorist himself a product of his humor. Followed by no redeeming value whatsoever, his failure should be sugarcoated with the historical obligation of a fool who should "be good sports to the extent that he laughs along or remains silent. In short, he must learn to "take" it" (Wilson, 2008, p. 8o). But as all those who have watched the film know, Arthur's inability to do so eventually leads him into incorporating the ultimate darkness that Gotham's Arkham Asylum conceals within its walls. 
Living the "Great American Joke" which acknowledges the incongruities between what is real and what is ideal, the comic modalities in a post-millennium USA confront an insatiable hunger for ironic detachment, revealing "the complexity of our problems while exposing the often reductive rhetoric in public discourse that itself refuses to solve" (Ezell, 2016, p. 147). Therefore, comedy might not only propel progress but also freeze it. At times, it can be a launching pad that signals a point of departure - a new topic for interpretative observation - and it can also be the landing platform that suggests a suspension of all flights - all other probable versions of surveying a proposed setback. As a result, to conceal the "psycho-physiological consequences of capitalist modernity, geopolitical displacement, and varieties of social death" (Ferguson and Ford, 2008, p. 240), a genre of gallows humor is selectively introduced that encourages political aloofness and champions mass diversion.

\section{Being 'Special' and Schadenfreude}

The Orwellian year (1984) in the USA which is close to the timeline of the Joker universe had witnessed the emergence of a somewhat nonchalant post-apocalyptic humanity with concepts like Cold War, governmental manipulation, corporatism, communism, and surveillance cameras still on the brink of their birth but not experienced as realities. It was more like a delayed realization of Huxley's Brave New World (1982) where technological sponsorships made products out of their consumers - creating extreme 'fun' worlds, new assumptions, new aesthetics, and image-oriented episodic delights - deflating the subjective nature of comedy. It further produced a dichotomy of political theatre and apolitical merry-go-round - promoting "an environment where cheerfully disconnected facts and fictions swirl in the same space” (Garber, 2017, para. 15) - begetting forms of humor that are a contributory agent of the body politic itself while denying to be so. For a nation to be complacent and pliable, it is important to innovate and renovate distracting narrations of celebrity peccadilloes or sensational crime stories, but mostly a sense of 'edgy' entitlement at the debilitating loss of an opposition party/soccer team/university/the 'other' of any kind. Here, Arthur ironically named after the legendry King Arthur is not a knight in shining armor venturing off to a quest for the Holy Grail but an 'other'; a comic Prufrock; a schadenfreude toy too enthusiastic to be recognized as someone special:

As being 'special' becomes increasingly integral to financial and emotional survival under neoliberalism, then it's no wonder that those seen as sauntering in and grabbing specialness off the counter instead of working for it or being "born that way" are felt to be so threatening. (Berlant, as cited in Markbreiter, 2019, para. 24)

All in all, the present paradigm of cultural customization advocates a 'spitegeist' of schadenfreude, developing a swarm intelligence obsessed with: restless internet trolls roaming about the nooks and crannies of different websites; viral blogs and op-eds on Nicki Minaj's butt implants exploding during a live performance; celebrity gossip sites, meme pages and paparazzi tabloids casually covering Kim Kardashian in a latex swimsuit; Kanye West confirming that indeed, he voted for himself; Nick Jonas not willing to dance to "Bole Chudiyan" yet again with Priyanka Chopra Jonas; ex-Disney star Orlando Brown being arrested in his underwear by bounty hunters; Bill Clinton and Monica Lewinsky having fun; George W. Bush slipping in and out of town as poodle naps; Donald Trump's tweet on 'covfefe' uniting a bewildered nation; Kamala Harris wishing Mr. Trump a "Happy Second Impeachment Day,” or Taylor Swift's gym appointment colliding with Justin Bieber's. Here, the stampedes of irrelevant information, public shaming and mutual intolerance online do not extrapolate a private moral dilemma, but a communal rhetoric. A more alarming kind of schadenfreude seems to be in full effect in the current American political scenario as particularly 
revealed in its 2016 election with Trump's presidential campaign as the apple of the international apparatus's eye, for in this case a collective schadenfreude not only promoted biased media coverage but also directly influenced a wide-ranging political outcome.

\section{Conclusion}

Joker's world as imagined by its writers, Todd Phillips and Scott Silver might be a fictional figment of the Batman series, false and outlandish. Yet the verisimilar appeal of the movie resonates a sense of distorted selfhood through the protagonist's fixation with comedy shows in which all the world is not just any stage, but a comic stage too. The hundreds of possible loci that make a certain act comedic are extremely complex and not perceivable in their entirety. Likewise, laughter, too, is not a uniform sign that the performer's intention has been duly received. On that account, the divergent views on the many hues of humor illustrate the Daedalian process of writing and producing contents that will make target viewers laugh- an undertaking further complicated by the media industry. Nonetheless, to navigate and understand who we are to ourselves and each other, it is important "to think afresh about the work the much-maligned emotion of schadenfreude does for us in all its comic versions and what it tells us about our relationships" (Smith, 2018, para. 22). Hence, once Joker taunts his viewers or arch-nemesis Batman in the latter installments (including the 2008 sequel, The Dark Knight casting Heath Ledger) and pulls up a sardonic smile asking, "Why so serious?" perhaps we could use a Cassandric pause to consider and reconsider a far greater dilemma, "Why not, occasionally?"

\section{References}

Berlant, L. \& Ngai, S. (2017). Comedy has issues. Critical Inquiry, 43(2), 233-249. https://doi.org/10.1086/689666

Ezell, S. K. (2016). Humor and satire on contemporary television: Animation and the American joke. Routledge Press.

Ferguson, M. A., \& Ford, T. E. (2008). Disparagement humor: A theoretical and empirical review of psychoanalytic, superiority, and social identity theories. Humor 21(3), 283-312. https://doi.org/10.1515/HUMOR.2008.014

Garber, M. (2017, April 27). Are we having too much fun? The Atlantic. https://www.theatlantic.com/entertainment/archive/2017/04/are-we-having-too-much-fun/523143/

Markbreiter, C. (2019, March 22). Can't take a joke: An interview with Lauren Berlan. The New Inquiry. https://thenewinquiry.com/cant-take-a-joke/

Ortony, A., Clore, G. L., \& Collins, A. (1988).The cognitive structure of emotions. Cambridge University Press.

Phillips, T. (Director).(2019). Joker [Film].Warner Bros. Pictures.

Puschak, E. [Nerdwriter1]. (2017, June 14). Check your schadenfreude [Video]. YouTube. http://y2u.be/Tvaoxq-eDvI

Pye, G. (2006). Comedy theory and the postmodern. Humor, 19(1), 53-70. https://doi.org/10.1515/HUMOR.2006.003 
Smith, H. R., \&Dijk W. van W. (2018). Schadenfreude and Gluckschmerz. Emotion Review, 10(4), 293-304. https://doi.org/10.1177/1754073918765657

Smith, T. W. (2018, November 21). Not just a German word: A brief history of schadenfreude. Literary Hub. https://lithub.com/not-just-a-german-word-a-brief-history-of-schadenfreude/

Ufberg, M. (2015, 30 March). The allure-and danger-of comedy roasts. Washington Post. https://psmag.com/social-justice/why-we-love-to-make-fun-of-justin-bieber

Wilkinson, A., Romano A., Frank, A., \& Polo, S. (2019, October 14). Did Joker deserve all the discourse? Vox. https://www.vox.com/culture/2019/10/14/20906190/

Williamson, L. E. (2008). Contentious comedy: Negotiating issues of form, content, and representation in American sitcoms of the post-network era [Doctoral dissertation, Glasgow University]. http://theses.gla.ac.uk/id/eprint/496

Wilson, N. A. (2008). Was that supposed to be funny? A rhetorical analysis of politics, problems and contradictions in contemporary stand-up comedy [Doctoral dissertation, Iowa University]. https://doi.org/10.17077/etd.hxtp16rn

Nishat Atiya Shoilee is a Lecturer in the Department of English and Humanities at the University of Liberal Arts Bangladesh, Dhaka. She is also a Sub-editor at the Star Literature and Review pages of The Daily Star, the largest circulating daily English-language newspaper in Bangladesh. She has translated/edited multiple manuscripts and published articles in refereed journals. Her research concentrates on cultural studies, comparative literature, diaspora studies, and digital humanities. 